\title{
Multidisciplinary Engagement with Nanoethics Through Education-The Nanobio-RAISE Advanced Courses as a Case Study and Model
}

\author{
Daan Schuurbiers • Susanne Sleenhoff • \\ Johannes F. Jacobs $\cdot$ Patricia Osseweijer
}

Received: 21 July 2009/Accepted: 4 November 2009/Published online: 21 November 2009

(C) The Author(s) 2009. This article is published with open access at Springerlink.com

\begin{abstract}
This paper presents and evaluates two advanced courses organised in Oxford as part of the European project Nanobio-RAISE and suggests using their format to encourage multidisciplinary engagement between nanoscientists and nanoethicists. Several nanoethicists have recently identified the need for 'better' ethics of emerging technologies, arguing that ethical reflection should become part and parcel of the research and development (R\&D) process itself. Such new forms of ethical deliberation, it is argued, transcend traditional disciplinary boundaries and require the active engagement and involvement of both nanoethicists and nanoscientists with the broader issues surrounding technological developments.
\end{abstract}

D. Schuurbiers $(\bowtie) \cdot$ S. Sleenhoff $\cdot$ J. F. Jacobs

P. Osseweijer

Working Group on Biotechnology and Society,

Department of Biotechnology,

Delft University of Technology,

Julianalaan 67 ,

2628 BC Delft, The Netherlands

e-mail: d.schuurbiers@tudelft.nl

D. Schuurbiers $\cdot$ S. Sleenhoff $\cdot$ P. Osseweijer

Centre for Society and Genomics,

Nijmegen, The Netherlands

D. Schuurbiers $\cdot$ S. Sleenhoff $\cdot$ J. F. Jacobs $\cdot$ P. Osseweijer

Kluyver Centre for Genomics of Industrial Fermentation,

Delft, The Netherlands
Whereas significant research efforts into multi- and interdisciplinary collaborations during R\&D processes are now emerging, opportunities for encouraging multidisciplinary engagement through education have remained relatively underexplored. This paper argues that educational programmes could be a natural extension of ongoing collaborative research efforts 'in the lab' and analyses how the Nanobio-RAISE courses could be used as a model for course development. In addition to exploring how the elements that were conducive to multidisciplinary engagement in this course could be preserved in future courses, this paper suggests shifting the emphasis from public communication towards ethical deliberation. Further course work could thus build capacity among both nanoscientists and nanoethicists for doing 'better' nanoethics.

Keywords Nanoethics · Ethics of emerging technologies · Education - Course design · Multidisciplinary engagement $\cdot$ Interdisciplinary collaboration $\cdot$ Interactional expertise

\section{Introduction}

This paper presents and evaluates two postdoctoral advanced courses organised in Oxford as part of the European project Nanobio-RAISE and suggests using their format to encourage multidisciplinary 
engagement ${ }^{1}$ between nanoscientists and nanoethicists. $^{2}$ The reason for encouraging multidisciplinary engagement derives from a recent scholarly debate concerning the ethical assessment of emerging technologies. Several ethicists have recently identified the need for 'better' ethics of emerging technologies. Appropriate ethical assessment of emerging technologies, it is argued, requires that ethical deliberation become part and parcel of the $R \& D$ process and demands increased collaborations between nanoscientists and nanoethicists. This paper will suggest pedagogical support for such increased collaboration by building on an existing course model that proved successful in bringing together participants with very diverse backgrounds and building interactional expertise between them. This course model will be analysed and used as a model for further course development. Before going into the details of these courses, the following section will outline why scholars have indicated the need for a better nanoethics and what it entails.

\section{Promises of Nanotechnology}

It is difficult to overstate the expectations that have surrounded the emergence of nanotechnology in recent years. It has been hailed as the next industrial revolution comparable to electrification or the steam engine $[35,39,53]$, providing unparalleled technological and social progress in almost any field imaginable. Nanotechnologies are repeatedly claimed to provide radical advances in medical diagnosis and treatment [31], electronics [1], cheap sustainable energy [8], environmental remediation [21], more

\footnotetext{
1The term 'multidisciplinary' is used here (as opposed to interdisciplinary) to indicate collaborations between actors from different disciplines without necessarily envisioning full integration of those disciplines. 'Engagement' is used (instead of 'interaction' or 'collaboration') to encompass the attitudinal component of multidisciplinary work: the actors' enthusiasm and willingness to learn from disciplines beyond the individual field of expertise.

${ }^{2}$ Strictly speaking, the terms 'nanoscientists' and 'nanoethicists' are overly narrow delimitations of the intended target groups; 'nanoscientists' refers to scientists, engineers and other researchers from the natural sciences involved in nanotechnological research; 'nanoethicists' refers to those scholars from the social sciences and humanities who have taken nanotechnological research broadly as their object of study. For purposes of readability we will however stick to these shorthand notations.
}

powerful IT capabilities [3], and improved consumer products [25]. Whether or not these promises will hold true, they have served to generate considerable investments: worldwide R\&D funding of nanotechnology was approximately 14 billion US dollars in 2007 and rose to 18 billion in 2008 [24]. As research into diverse areas of applications continues, a range of nano-enabled consumer products like sunscreens containing nanosized titanium dioxide and food storage containers with nanosilver is entering the market [51]. The world market for such products was around 150 billion US\$ in 2007 and is forecast to grow to $\$ 3.1$ trillion in 2015 [23].

Despite the promises of nanotechnology, expectations and investments have been accompanied by expressions of doubt and concern ever since the ignition of the nano-boom in the early years of the 21 st century. Concerned scholars have argued that if this emerging technology is indeed as revolutionary as promised, it would be wise to assess its wider ethical and societal ramifications. In addition to uncertainty about the human and environmental health risks of nanoparticles [12, 16, 36], and regulatory challenges [7], nanotechnology was feared to pose deeper ethical challenges with respect to human enhancement [5], equity [47], privacy [20] and security [2].

Leaving aside the question of whether these ethical issues are essentially 'new' or rather reiterations of an ongoing debate [46], large numbers of scientists, ethicists and policy makers in the early years of the 21 st century seemed to agree that nanotechnology wasn't 'business as usual' and called for ethical assessment. Moreover, failure to address the broader ethical and social dimensions of nanotechnology was generally feared to unleash a 'social backlash' against nanotechnology similar to the case of genetically modified crops in Europe. The UK Royal Society and Royal Academy of Engineering nanotechnology report of 2004 noted:

'As recent debates in the UK and elsewhere demonstrate, developments in science and technology do not take place in a social and ethical vacuum. Widespread discussions of issues such as nuclear energy, agricultural biotechnology and embryonic stem cells illustrate this point only too clearly. ... Given this backdrop, it seems highly likely that some nanotechnologies will raise significant social and ethical concerns.' ([41], p. 51). 
Although the assumption that nanotech will be "the next GM' has been contested [42], the potential for a social backlash against nanotechnology encouraged policy makers to demand attention for the broader dimensions of nanotechnology, giving rise to a new field of social and ethical enquiry. From the outset, the aim of this burgeoning field of nanoethics has been to 'close the gap' between the accelerated speed of developments in nanotechnology and its ethical assessment [29]. But due to the intrinsic novelty of the technologies as well as deep uncertainty about future directions and possible impacts of the research, the appropriate role and remit of this developing discipline has remained a matter of considerable debate [52]. Nanoethics has been criticised for speculating about improbable futures and strengthening the hype and myth of nanotechnology by if-andthen reasoning [32]. If traditional methods for ethical deliberation and assessment lag behind the speed of development of new technologies, then what is needed for nanoethics to 'catch up'?

\section{'Better' Nanoethics?}

In response to these challenges, several leading ethicists have recently proposed a re-examination of the processes of ethical deliberation in light of the very nature of emerging technologies. Engineering ethicist Joe Herkert has analysed the propositions of both computer ethicist James Moor and bioethicist George Khushf for a 'better' nanoethics that can keep pace with the ethical challenges of emerging nanotechnologies (Herkert 2009, unpublished manuscript). Moor [30] argues that anticipated 'major technological upheavals' require '....Better ethical thinking in terms of being better informed and better ethical action in terms of being more proactive.' He suggests three improvements: first, the acknowledgement that 'ethics is an ongoing and dynamic enterprise;' second, the employment of a multidisciplinary approach that includes 'better collaborations among ethicists, scientists, social scientists, and technologists;' and finally, the development of 'more sophisticated ethical analysis.' Herkert notes how bioethicist George Khushf has similarly suggested redefining traditional methods of ethical reflection in light of radical ethical challenges put forward by the radical possibilities associated with new technologies: 'Faced with the prospect of increasingly accelerating, radically new technologies, we must completely reassess how ethical issues are addressed and how ethical debate informs broader public and legal policy.' Emerging technologies thus pose: 'an ethical challenge not just in the number, scope, and depth of issues that are raised but also in the very form that ethical reflection takes.' ([22] p. 258). For both Khushf and Moor, 'better' nanoethics requires both that ethical reflection should become more tightly integrated with the $R \& D$ process itself, and requires increased collaborations through new multidisciplinary engagements between nanoscientists and nanoethicists. Herkert's representation of the views of Moor and Khushf, particularly the suggestion to reassess the very form that ethical reflection should take, links in with the views of Nordmann and Rip [33] who recently argued for a 'more focused approach' in nanoethics that 'could lead to more meaningful interactions' between scientists and ethicists.

While the theoretical contours of 'doing' nanoethics differently are slowly becoming visible - notably the vision of bringing ethical assessment 'closer' to R\&D processes and increasing collaborations between nanoscientists and nanoethicists - precisely how to implement this broad vision is as yet unclear. In 1959 the British physicist C.P. Snow introduced his now famous notion of the 'Two Cultures' in his Rede lecture, arguing that the divide between the sciences and the humanities was a 'hindrance to solving the world's problems' [48]. Fifty years later, the two cultures seem to be more strongly separated than ever with respect to the topics addressed, questions asked, methods used and worldviews. Although new forms of collaboration between natural scientists and engineers and social and human scientists are emerging in various places [18, 43] and recent studies suggest that nanotechnology researchers appear receptive to ethical issues in relation to nanotechnology [27], multidisciplinary engagement between nanoscientists and nanoethicists still faces significant challenges. Due to differences in training and cultural 'formation' between the disciplines, it has proven very difficult to establish common ground for meaningful discussion between nanoscientists and nanoethicists. Reflection on the broader dimensions of research does not form an integral part of lived practices in the laboratory as a consequence of both long-standing institutional arrangements and educational structures that have fostered a 'laissez-faire' attitude with respect to engaging with the broader dimensions of research [4, 28]. Particularly young 
researchers often operate in a 'protected space', effectively shielded from outside pressures by their lab directors [37]. Senior researchers are hesitant to add social and ethical 'digressions' to already extremely demanding science curricula. Conversely, nanoethicists have in some cases been hesitant to 'get their hands dirty' and have preferred to engage in theoretical reflection and conceptual analyses rather than engaging with research practices directly $[19,26]$. Here, as in the natural sciences, the academic careers of young researchers largely depend on publications in traditional, mostly monodisciplinary journals.

Bringing ethical assessment closer to R\&D practices will thus at some point require the rapprochement of the Two Cultures. This remains a major challenge, one that depends both on further research into interdisciplinary collaborations (defining new forms of multidisciplinary engagement in the laboratory) and on training initiatives (building the appropriate knowledge, skills and attitudes that the actors require in order to engage). Indeed, innovative approaches are emerging in various places that aim to bridge the cultural divide between the sciences and humanities such as trading zones [18], scenario workshops [38], midstream modulation $[16,43]$, ethical parallel research [54], biographical narratives [10], and initiatives aimed at increasing the 'moral imagination' of researchers [51]. These interdisciplinary research initiatives largely focus on collaborations during the $\mathrm{R} \& \mathrm{D}$ process itself.

In addition to researching the processes by which actors engage in multidisciplinary collaboration, the capacities of actors (i.e. the appropriate knowledge, skills and attitudes) are fundamental prerequisites as well. The National Science Foundation has stressed the need for building such broader capacities for integration among the academic workforce as a condition for the responsible development of nanotechnology: 'Many nontechnical advanced students will need to learn about nanotechnology, and future nanoengineers will need to study the ethical and societal implications of their work.' [40]. The 'Opinion on the Ethical Aspects of Nanomedicine' of the European Group on Ethics in Science and New Technologies to the European Commission suggests to:

'cluster experts from different fields, promote deeper understanding of the ethical issues arising from nanotechnology and nanomedicine, promote education in the fields above, and facilitate interaction between the community of ethicists and nanotechnologists and the embedding of ethics into research practices.' ([14], p. 61).

Whereas the need to build capacity for multidisciplinary work is thus widely recognized, the potential for encouraging multidisciplinary engagement in educational settings has thus far remained relatively underexplored. This paper therefore suggests an extension of ongoing explorations into new forms of ethical deliberation in the lab by providing pedagogical support for multidisciplinary engagement between nanoscientists and nanoethicists [45, 50]. Our aim here is to complement ongoing research efforts with dedicated course work, building on an existing course model that proved successful in bringing together participants with very diverse backgrounds and building interactional expertise between them. We will present and evaluate two advanced courses organised in Oxford as part of the Nanobio-RAISE project below. The courses created a multidisciplinary learning environment for nanoscientists and nanoethicists through engagement with nanotechnology and its broader societal and ethical dimensions. We will focus on the advantages and drawbacks of this particular type of design, and will suggest in what way theses types of courses might be used as a model to encourage improved nanoethical deliberation.

\section{Nanobio-RAISE}

The courses were organised as part of the European project Nanobio-RAISE, a 6th Framework Programme Science and Society Co-ordination Action funded by the European Commission from November 2005 until October 2008. This project aimed to combine science communication with ethics research in nanobiotechnology. The project was developed in response to a specific call from the Commission which had recognised the need for responsible development of nanotechnologies in its Communication Towards a European strategy for nanotechnology where it stressed that:

'Nanotechnology must be developed in a safe and responsible manner. Ethical principles must be adhered to and potential health, safety or 
environmental risks scientifically studied, also in order to prepare for possible regulation. Societal impacts need to be examined and taken into account.' ([13], p. 3).

The Commission had also taken up the development of model courses: in order to raise the awareness of researchers in the field of ethics' as an explicit action point in its Science and Society Action Plan ([12], p. 22).

The Nanobio-RAISE project therefore brought together in 2005 a multidisciplinary group of nanotechnologists, ethicists, social scientists and communication specialists with the aim to horizon-scan for developments likely to cause concern, clarify the ethical issues involved and carry out strategies for public communication to address the emerging questions. These objectives were implemented by means of a series of meetings of an expert working group on human enhancement [5], three horizon-scanning workshops, a series of convergence seminars aimed to assess public opinion in the four corners of Europe [17], a citizen engagement activity using the DEMOCS game [6], four sets of briefing papers, an information and dissemination programme and two international advanced courses on 'Public Communication and Applied Ethics of Nanotechnology' [44]. See also Fig. 1 for an overview of the project components. ${ }^{3}$

\section{Two Nanobio-RAISE Advanced Courses}

As one key component within the overall NanobioRAISE project, two five-day residential advanced courses on 'Public Communication and Applied Ethics of Nanotechnology' were organised. Both courses were held at St. Edmund Hall, Oxford, UK, on 11-16 March 2007 and on 23-28 September 2007 respectively. ${ }^{4}$ The courses were developed on the basis of a series of earlier courses on public perceptions of biotechnology [34] and aimed 'to

\footnotetext{
${ }^{3}$ Further information on the results of the Nanobio-RAISE project can be found on the project website: http://nanobioraise.org/.

${ }^{4}$ The Nanotechnologies Industry Association organised a similar course in collaboration with Cambridge Biomedical Consultants and with funding from the UK Royal Academy of Engineering on 22-27 March 2009. Although this course was modelled after the Nanobio-RAISE courses, its particular setup and programme falls outside the scope this paper.
}

increase knowledge and awareness of the ethical, legal and social aspects of nanotechnology' and 'to enable the participants to carry out a wide variety of public communication activities discussing the wider implications of their work with confidence'.

The specific learning objectives of these one-week, intensive courses were to provide to the participants knowledge of the relevant ethical, legal and social aspects of nanotechnology; skills to communicate effectively with interlocutors outside the peer community including the media and lay audiences; and a broad understanding of 'horizontal' issues involved in public awareness and perceptions of nanobiotechnology. The results from the other activities performed within the Nanobio-RAISE project fed back into the course content and design.

The courses brought together some twenty-five postdoctoral researchers and faculty from a range of nanotechnology related fields and disciplines. Participants came from a wide range of backgrounds including nano/biotechnologies, medical sciences, chemistry, physics, law, science communication, and philosophy (see Fig. 2). In each case, approximately two thirds of the participants were natural scientists and engineers and one third were from the social sciences and humanities; two thirds were working in academia and one third in industry.

\section{The Course Programme}

The course programme combined lectures on nanotechnology and its ethical, legal and social dimensions with practical and hands-on training. ${ }^{6}$ The specific topics and activities scheduled in the course will be discussed directly below, followed by an evaluation of the course and discussion of the central elements identified as encouraging multidisciplinary engagement.

\section{Course Topics}

To enable a common ground for meaningful discussion of the broader dimensions of nanotechnology, the course programme provided a broad overview of both the state of the art in nanotechnological research and

\footnotetext{
${ }^{5}$ See the course programme at http://files.nanobio-raise.org/ Downloads/nbrp2.pdf. Accessed 20 July 2009.

${ }^{6}$ A detailed programme is provided in the Appendix.
} 


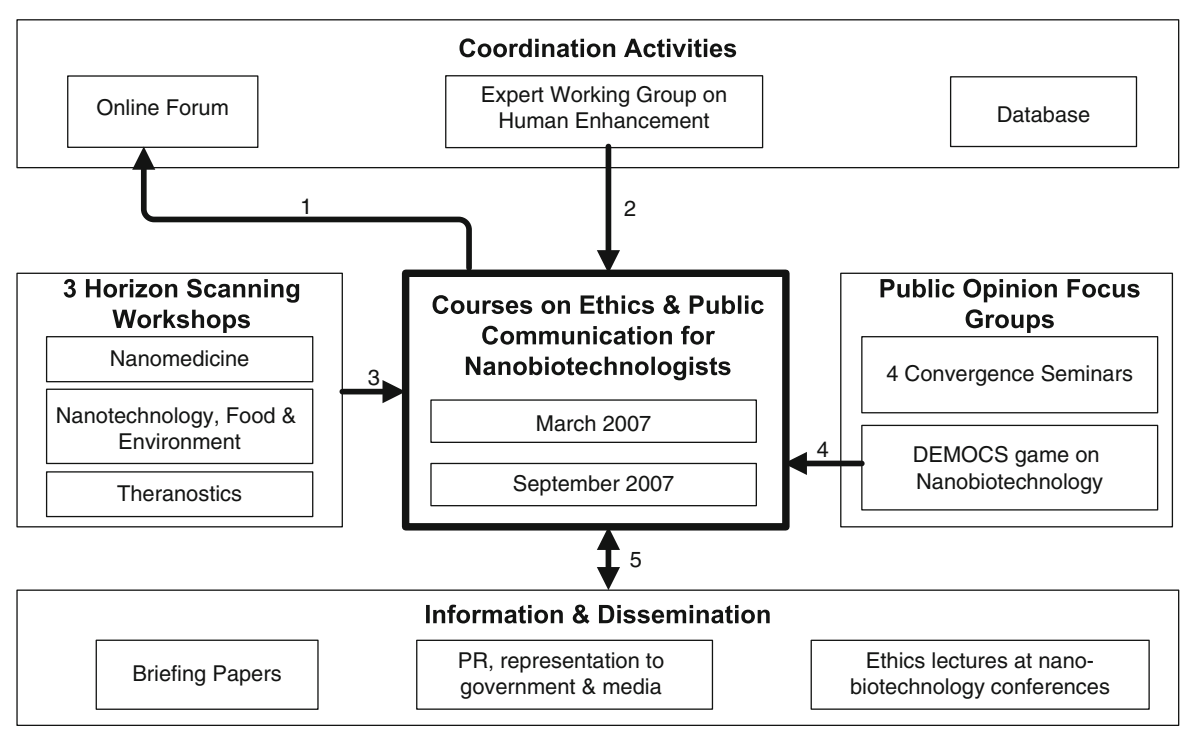

Fig. 1 Schematic overview of the Nanobio-RAISE project. Arrows represent relations between the different work packages and the course: 1 . The website and online forum facilitated further contact between course participants. 2. Results from the Expert Working Group were used as input for the courses. 3. Results from the Horizon Scanning Workshops were used as input for the courses. 4. The Deliberative Meetings of Citizens (DEMOCS) game was played during the course. 5. The course was presented during conferences to discuss the format and results. Participants also organised follow-up activities using the course material as input

a comprehensive overview of actual and possible future developments in the field.

In addition to raising general interest and awareness of the broader ethical, legal and social issues surrounding nanotechnology, the course programme aimed to explore how these issues could be related to nanoscientific practices. The course material therefore aimed to enable nanoscientists to make direct links
Fig. 2 Backgrounds of participants of the two Nanobio-RAISE courses $(n=42)$

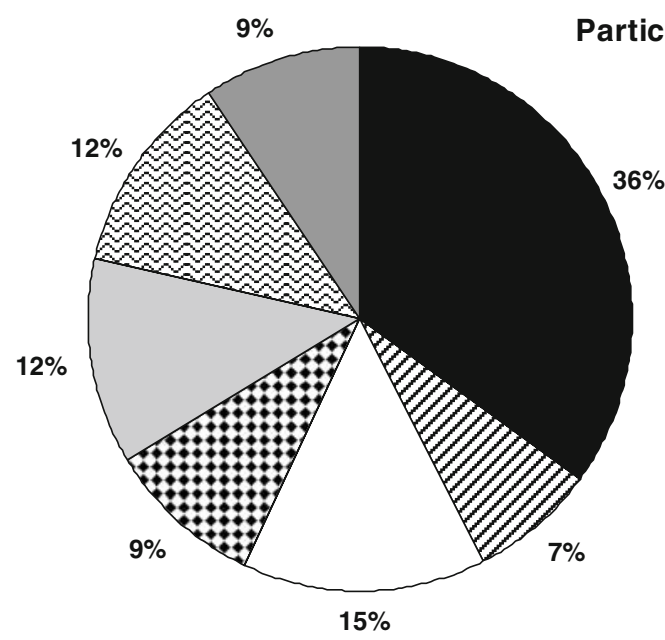

Participants - Backgrounds

Nano/ Biotechnology

36\% $\square$ Chemistry

$\square$ Medical sciences

Q Physics

$\square$ Law

Science

Communication

Philosophy 
Table 1 Topics covered in the course programme

\begin{tabular}{l} 
Nanoscience and technology-the state of the art \\
Nanobiotechnology \\
Nanomedicine \\
Nanotechnology in food \\
Ethical, legal and social issues \\
Nanoethics \\
Law and regulatory affairs \\
Toxicology and risk assessment of nanoparticles \\
Public policy development for nanotechnology \\
Commercialisation of nanotechnology \\
Nanotechnology and developing countries \\
Public perceptions of nanotechnology \\
Public opinion surveys \\
Risk perceptions and attitudes \\
Learning from the GM debate \\
Science Communication \\
Communication stategies \\
Nanotechnology, PR and the media \\
How do the media work? \\
\hline
\end{tabular}

with their work without assuming extensive training in ethics or social sciences - and vice versa: providing a scientific knowledge base to social scientists and humanists without offering too much scientific detail. Both lectures and activities therefore aimed to stay close to the lived experience of the researchers. Leading representatives from diverse areas of nanotechnological research were invited to share personal encounters with the broader issues - a researcher in nanomedicine would describe the hurdles to approval of a new drug for instance. Participants were also encouraged to discuss how they thought the issues were related to their own work.

\section{Hands-on Activities}

A series of practical activities were integrated in the programme to enable the participants to carry out a variety of basic communication activities, discussing the state of the art as well as the ethical, legal, and social implications of their work (see Table 2). By discussing and practicing with each other, participants also learned to interact with researchers from other disciplines. The activities will be described below, followed by evaluations from participants.

\section{Introductory Presentations}

Each participant presented their prime personal objective for this course during a brief introduction at the beginning of the course. Participants predominantly stated that they wished to enhance their skills to communicate with the public, but also indicated an interest in the ethical, legal and social concerns surrounding nanotechnology. These personal objectives were discussed halfway through the course and at the end: participants were asked whether their objective was addressed and what needed further attention, which unexpected learning elements they had experienced and whether this had changed their objective.

\section{DEMOCS Game}

Participants played the DEMOCS (DEliberative Meetings Of Citizens) card game on nanobiotechnology created for the Nanobio-RAISE project in collaboration with the New Economics Foundation which devised the concept in 2002. DEMOCS is a novel form of lay participation in the form of a card game around which participants discuss for approximately two hours and come to agreed or divergent views on national or local policy issues or on general principles. ${ }^{7}$ Examples of applications discussed by way of the game were using nanotechnology to assist in early diagnosis; targeted drug delivery; tissue regeneration; fortifying foods; and human enhancement [6].

\section{Debate Session}

A debate session was held on the second day of the course in the form of a 'House of Commons Debate', with two parties defending or opposing a number of statements. Participants had submitted 'debatable' statements (i.e. statements that one can reasonably be either for or against and are not likely to leave all participants on one side) about nanotechnology before the start of the course. During a strictly timed session an anonymised selection of these statements was debated. Examples included: 'Public acceptance of nanomedicine depends first and foremost on the

\footnotetext{
${ }^{7}$ The game was originally devised with sponsorship from the Wellcome Trust by Perry Walker of the new Economics Foundation, in consultation with experts in ethical and social issues and in innovative engagement with publics.
} 
Table 2 Hands-on activities within the course

\begin{tabular}{|c|c|c|}
\hline Activity & Description & Duration \\
\hline $\begin{array}{l}\text { Introductory } \\
\text { presentations }\end{array}$ & $\begin{array}{l}\text { Participants present their } \\
\text { prime personal objective } \\
\text { in a brief presentation to } \\
\text { the group }\end{array}$ & $\begin{array}{l}15 \mathrm{~min} \text { each; } \\
2,5 \mathrm{~h} \text { total }\end{array}$ \\
\hline $\begin{array}{l}\text { DEMOCS } \\
\text { game }\end{array}$ & $\begin{array}{l}\text { Deliberative Meetings of } \\
\text { Citizens card game in which } \\
\text { players discuss ethical } \\
\text { dilemmas regarding new } \\
\text { technologies }\end{array}$ & $2 \mathrm{~h}$ \\
\hline Debate session & $\begin{array}{l}\text { A 'House of Commons' } \\
\text { debate in which two parties } \\
\text { defend or oppose statements } \\
\text { submitted by the participants }\end{array}$ & $2 \mathrm{~h}$ \\
\hline Role play & $\begin{array}{l}\text { Re-enacting political decision } \\
\text { making processes by playing } \\
\text { out roles of various } \\
\text { stakeholder groups }\end{array}$ & $2 \mathrm{~h}$ \\
\hline $\begin{array}{l}\text { Communication } \\
\text { plan }\end{array}$ & $\begin{array}{l}\text { Participants work in break- } \\
\text { out groups and present } \\
\text { communication plans for } \\
\text { their fictitious company }\end{array}$ & $\begin{array}{l}1 \text { day (several } \\
\text { sessions) }\end{array}$ \\
\hline Media training & $\begin{array}{l}\text { Participants are trained in } \\
\text { writing and presenting their } \\
\text { work to a lay audience. }\end{array}$ & 1,5 day \\
\hline
\end{tabular}

communication of factual descriptions of this newly emerging field;' 'Nanotechnology will be the new GM;' Nanotechnologies should, but currently do not, address health issues in developing countries'. The aim of the exercise was both to get acquainted with the different perceptions and attitudes within the group and to learn to explain oneself to a multidisciplinary audience.

\section{Role Play}

The role play session on the third day consisted of the re-enactment of political decision making processes on controversial technologies. By playing out the role of various stakeholder groups, participants were encouraged to discuss the logic of different types of rational argumentation. In particular, this exercise introduced the different visions that various stakeholders in the debate may have.

\section{Communication Plans}

The drafting of a communication plan was integrated in the course as a central element in the hands-on training. This activity ran throughout the course, with dedicated sessions for group work over several days. Participants worked in small groups on a communication plan for their fictitious company (a university spin off, a small consultancy, a medium-sized enterprise, a multinational corporation and a non-governmental organisation) with the assignment to draft a structured communication plan, following general instructions on a handout. Halfway through the course, students presented their preliminary plans upon which a 'nasty situation' followed, an unexpected event such as an explosion, court trial or terrorist attack. These nasty situations all involved one of the other companies, encouraging communication and negotiation between the groups. Final presentations, presented on the last evening, needed to address this nasty situation as well as incorporate the lessons learned from the lectures earlier in the week. ${ }^{8}$

\section{Media Training}

The media training was held at the end of the week. An experienced radio broadcaster and a science journalist trained the participants in writing and presenting their work to a lay audience. The day started with a simulated press conference, in which participants assumed the role of reporter and had to write a short piece for their local magazine on the visit of a well-known scientist. In the afternoon, the press releases that participants had prepared in advance were discussed, and at the end of the day participants tested their verbal skills during a simulated radio interview. Participants were informed on how the media works, including the day-to-day realities that journalists have to work with-approaching deadlines, quick decisions, and stubborn editorsand how to maintain good media relations.

\section{Social Networking}

The social networking - that naturally occurs during a five-day intensive course - was facilitated deliberately by extended stay of lecturers, residential stay, and combined social activities. This facilitated information-

\footnotetext{
${ }^{8}$ The assignment also functions as a competition: each participant can buy or sell 'shares' in another company (not their own); all companies start out even, and shares are bought and sold after the presentations. A panel of experts, with considerably more shares, place their shares after evaluating the final presentations as well. The company that manages to accumulate most shares, wins.
} 
sharing among participants and lecturers so that in addition to the stand-alone course module itself, participants were encouraged to entertain relations with scholars from other fields during and after the course. In order to facilitate a longer term networking environment for further discussion and activities within the group a Nanobio-RAISE Hyve was established shortly after the course on the popular social networking site Hyves.nl. Most participants enrolled in the Hyve and continued to share their thoughts, pictures, documents and further information including the lecturers' presentations.

Evaluation by Participants

Participants were asked for their feedback both during the course by way of a mid-term evaluation and after the course finished, through feedback forms. They evaluated the organisation, theoretical and practical programme and general aspects of the course very positively. Responses to the question 'What overall score would you give this course as a whole?' averaged 4.1 out of 5. Participants welcomed the integration of a practical, hands-on approach to the range of complex theoretical issues in ethics and social sciences through interactive work such as the role playing exercise and the debate session. They especially appreciated the quality and diversity of the lecturers, whose input, combined with the very diverse backgrounds of the participants themselves, they thought constituted a good learning environment and generated fruitful discussions. As one nanobiotechnologist noted: 'This was the other side of science that I had missed seeing all these years. It's been a 'mind opening' course.' Participants enjoyed the group work, especially the debate session, communication exercise and introductory presentations. A postdoctoral researcher in the philosophy of science said: 'I am not a fan of group work generally, but here it gave lots of fun and insight.' The variety of backgrounds of participants was found to provide synergy to the group. A participating medical doctor noted that: 'It was not easy to cooperate due to diverse background knowledge. In the end, these diversions provided enormous synergies for the team work.'

Follow-up

The courses also facilitated longer-term networking, as can be seen from a variety of follow-up activities: one participant recently organised a very similar course in her home country; another participant organised a public outreach activity in Asia; several lecturers were involved in the supervision of a research project submitted by one of the participants; and many participants have kept in touch with each other. Although those contacts are mostly informal, several participants have drafted joint papers and built collaborative projects. In summary, the courses served to bring diverse audiences together. This is why we suggest using this format for encouraging multidisciplinary engagement between nanoscientists and nanoethicists.

\section{Discussion}

Considering the positive evaluations from participants and the range of follow-up activities, the courses provide a successful format for bringing together scholars with diverse backgrounds and laying the foundations for multidisciplinary engagement with the broader dimensions of nanotechnology. Particularly, the participation of a broad range of backgrounds proved to be a fertile breeding ground for multidisciplinary engagement. For this reason, we would like to suggest using the existing format of these courses to address the need identified aboveincreased collaborations between nanoscientists and nanoethicists - in an attempt to bridge the divide that exists between the two cultures. By creating a multidisciplinary learning environment and providing a broad knowledge base required for successful collaboration, such courses may complement ongoing interdisciplinary research efforts in the lab by providing participants with the necessary knowledge, skills and attitude to engage in multidisciplinary work. We will first suggest three central elements that in our opinion proved to stimulate multidisciplinary debate, and subsequently present some modifications that might gear future courses more towards the specific challenges for nanoethics.

Three Elements that Encourage Multidisciplinary Engagement

Looking back on the courses, we have identified three central elements that can build the interactional expertise [9] required for nanoscientists and nano- 
ethicists to engage in meaningful multidisciplinary dialogue about the topics at hand in the 'trading zone' of the ethical and social dimensions of nanotechnology [18]: first, providing a broad knowledge-base of relevant horizontal issues; second, building interactional skills among nanoscientists and nanoethicists; and finally, stimulating network building.

1) Multidisciplinary knowledge: Providing a broad knowledge-base of relevant horizontal issues.

The courses addressed a broad range of topics: beyond those that would strictly speaking fall within the category of 'ethics', it included those topics deemed necessary for ethical reflection in the broader sense of the word like the reasons for politicians to fund scientific programmes, the politics of science, the diffusion of new technologies in society, issues of public acceptance and the role of the media. A shared knowledge base among participants is a vital aspect to the integration of ethical deliberation with R\&D processes. By complementing the state of the art in science and reflection on its ethical issues with this broader picture that includes politics, public perceptions and the media, the course programme places scientific developments in their wider socio-political context, allowing for a convergence of perspectives from within and outside the science. By discussing and engaging with these different perspectives, participants do not only acquire a basic level of knowledge on the kinds of approaches to the technological developments at hand, but also obtain a deeper understanding of the different 'lifeworlds' that exist in different communities of expertise.

The breadth of topics necessarily comes at the cost of in-depth treatment. The unequal distribution of knowledge and expertise is to some extent unavoidable in multidisciplinary settings - due to symmetry of ignorance-so the challenge is to provide sufficient levels of information without losing the audience. From previous course evaluations it became clear that detailed philosophical analyses turned out to be beyond the level of comprehension of nanobiotechnologists and vice versa. Rather than speculating about distant futures, course topics could focus on less dramatic but more urgent and more realistic scenarios-issues of intellectual property, regulation, etc. As Nordmann and Rip [35] indicate: 'Scientists find it difficult to relate to the grand claims of speculative ethics, so a more focused approach could lead to more meaningful interactions.'

2) Multidisciplinary skills: building interactional skills among nanoscientists and nanoethicists.

In addition to the knowledge component, a second central element concerns the specific skills required for engaging with others outside the community of expertise such as being able to explain one's work without the use of jargon, to combine different perspectives on a topic and rhetorical skills. Particularly activities like the role play and debate session have served to help participants to come to understand and work with perspectives of other stakeholders in the debate. By opposing or defending different positions, the debate session establishes a common ground for discussion between the diverse disciplines present in the group. Interestingly, the debate session quickly demonstrates how 'facts' become subordinate to effective rhetoric in a multi-stakeholder debate, arguably reflecting 'real' public debates. The debate session also offers participants an opportunity to discuss their personal views and to engage in discussion about them. The role play offered another way in which participants were exposed to alternative visions: a scientist having to defend the perspective of a non-governmental organisation or a social scientist playing the role of a news reporter may come to see the internal logic of the position of another stakeholder. By interacting about contentious issues beyond the personal field of expertise, participants importantly experience how each is expert in one field and lay in another. The debate then serves to explore how different perspectives on the same topic can be brought together. These interactions all require rhetorical and performance skills which deserve and have been given special attention in a course where interaction and engagement are central.

3) Multidisciplinary attitudes: stimulating network building

With a view to seeing the course as a first step towards increased collaborations between experts from different disciplines, the overall attitude it engenders may ultimately be more important than the basic knowledge and skills it imparts. This is why we have used the term multidisciplinary engagement: indicating the importance of the willingness and enthusiasm to interact among participants.

The follow-up after the course shows that successful interactions during course work can lead to 
increased collaborations afterwards. The course should therefore not be a stand alone module, but rather functions as the start of a social network, encouraging members to stay in touch and collaborate. From the experience of previous similar courses the participants take what they have learned back to their colleagues and institutions, acting as 'amplifiers', undertaking and organising further outreach and representational activities and working to establish these approaches in the courses and activities of their own institutions.

\section{Modifications}

Having sketched this general outline on the basis of previous experience, some modifications with respect to the earlier courses will be required to gear the course towards the specific goal of engagement between nanoscientists and nanoethicists. The first modification would be to shift emphasis from public communication to deliberation on the broader dimensions of nanotechnology as they affect the $R \& D$ process itself. The emphasis of the previous courses, as part of the Nanobio-RAISE project, was more on training scientists to communicate the broader dimensions of their work to the media and the general public with confidence. One might say their focus was 'from the inside out': how to communicate the results of one's work to various audiences? This focus was reflected in the central role for the media training and the communication plan. The ethical, legal and social issues were introduced insofar as they supported the communication component, as a precondition for improved communication.

Although communication and interaction inevitably play an important role in all types of engagement with other stakeholders, the intention to bring ethical deliberation closer to the R\&D process itself necessitates a balancing act between an inside-out perspective and a view 'from the outside in': how to bring broader social and ethical considerations to bear on scientific work? The courses envisaged would focus on the collaborative exploration of ethical and social issues as they affect the R\&D process; the deliberative aspects will thus take precedence over the dissemination aspects. Insofar as public engagement would be addressed, the focus would be more on how to integrate public values in research decisions or in science policy, rather than on how to better inform the public about nanotechnological research. Our aim would thus be to 'open up' the research processes, exploring the ethical dimensions of research processes themselves and the question of how to address public values within these.

The emphasis on ethical deliberation instead of public communication invites the question of how to encourage nanoscientists to attend the course. Communication skills training suggests a direct benefit for nanoscientists: the ability to communicate effectively with the public is becoming an accepted requirement for furthering one's career in research. Indeed, most participants explicitly mentioned the acquisition of communication skills among their prime personal objectives. Increasing one's ethical deliberation skills may not have such immediate benefits, although participants did also express interest in learning more about the ethical issues surrounding their research. The ability to perceive and address relevant ethical issues might however become more important to acquiring research funding in the near futurefunding agencies increasingly require that attention be paid to ethical issues in research proposals. That said, further initiatives may be needed to convince nanoscientists of the relevance of ethical deliberation for their research. The question how to encourage scientists to participate in ethical deliberation efforts is a critical question and one that may need further support from lab directors and funding agencies.

In addition to the question of how to engage nanoscientists, the question of how to bring broad ethical consideration to bear on the 'micro-level' of individual research projects inevitably remains a challenge and will need to draw on ongoing policy and lab engagement studies. One possible way of modifying the current course programme could be by turning the communication plan exercise into a tentative 'midstream modulation' study [16] to collectively think through how ethical issues could be integrated in research decisions by merging the expertise of nanoethicists and nanoscientists in mini-research projects.

Another modification that could be useful from both a research and a pedagogical perspective is to pay close attention to the multidisciplinary learning that occurs during course work, monitoring the learning process by way of an ongoing 'opinion survey' during the course, to estimate if and to what extent participants' opinions on the relevance of other forms of expertise change in light of exposure to different perspectives. In addition to 
being a learning environment, the course then becomes a valuable source of research data in itself. This could be done by way of voting on participants' statements and monitoring for changes in opinion throughout the week.

A final point to consider is whether the type of multidisciplinary engagement envisaged in this paper will in fact serve as the stepping stone toward integrating ethical reflection with the $R \& D$ process itself. Although the kinds of follow-up initiatives undertaken by participants after the course do seem to indicate that networking and collaboration persists over time, it is as yet uncertain to what extent such engagement 'among colleagues' has led to interdisciplinary engagement 'in the lab'. Follow-up questionnaires that enquire for these questions on the longer term (several years after the course) could shed further light on the eventual integration of the lessons learned during the courses in daily research practices. Such long-term post-evaluations as have been held with respect to the courses predating the NanobioRAISE courses [34] suggest that participants keep using the course material up to several years after the course, but to what extent this will lead to significant changes with respect to integrating ethical reflection in research practices is still to be determined.

\section{Conclusion}

Multidisciplinary approaches towards ethical deliberation as envisaged in recent views on 'better' nanoethics - integrating ethical issues in the earliest possible stages of research and development of nanotechnology - will at some level depend on the knowledge, skills and attitudes of the actors involved. As the contours of better ways of doing nanoethics are slowly becoming visible, practical implementation still leaves open many questions, both at the level of training and of research. In this paper we have suggested how dedicated course work on multidisciplinary engagement could be used as a natural complement to ongoing multidisciplinary research efforts 'in the lab.' We have derived from the existing format of NanobioRAISE courses three central elements to encourage engagement between nanoscientists and nanoethicists and have suggested modifications to support 'better' ethical reflection, balancing the 'inside-out' and the 'outside-in' perspective.
To be sure, these are only the first steps towards the challenge of bridging the divide that exists between nanoscientists and nanoethicists. Transcending the barriers between the two cultures is likely to be one of the main challenges that the developing field of nanoethics is facing. It will require educational reform -increasing the capacity of scientists and engineers to recognize and address ethical and social issues in their work as well as the capacity of ethicists to bring ethical and social issues directly to bear on scientific work - as well as organizational reform-creating an institutional environment in which attention to the broader issues and increased collaboration is both encouraged and rewarded. Further explorations of different forms of multidisciplinary engagement may be indispensible in designing 'better' nanoethics.

Courses like the ones discussed here may assist in paving the way for multidisciplinary engagement. To do so we need to engage and involve nanoscientists with the broader dimensions of their work; urge nanoethicists to take a focused approach towards ethical dimensions of research; and explore the common ground between scientific and ethical expertise from which the wider ramifications of scientific developments can be assessed at the earliest possible stage. As Moor suggests: 'At the very least we need to do more to be more proactive and less reactive in doing ethics.' With these courses, we have aimed to do just that.

Acknowledgements Many thanks to David Bennett, Nanobio-RAISE project coordinator, for his advice and oversight during the course organisation and overall project management. All the lecturers and participants in the courses and the Nanobio-RAISE project members are gratefully acknowledged for their advice and contributions. Many thanks also to Ibo van de Poel and the members of the Working Group on Biotechnology and Society at Delft University of Technology for helpful comments on earlier versions of this text. This article is the result of the Nanobio-RAISE project funded by the European Commission under contract number 017534, and of a research project of the Centre for Society and Genomics and the Kluyver Centre for Genomics of Industrial Fermentation in the Netherlands, funded by the Netherlands Genomics Initiative.

Open Access This article is distributed under the terms of the Creative Commons Attribution Noncommercial License which permits any noncommercial use, distribution, and reproduction in any medium, provided the original author(s) and source are credited. 


\section{Appendix: Course Programme}

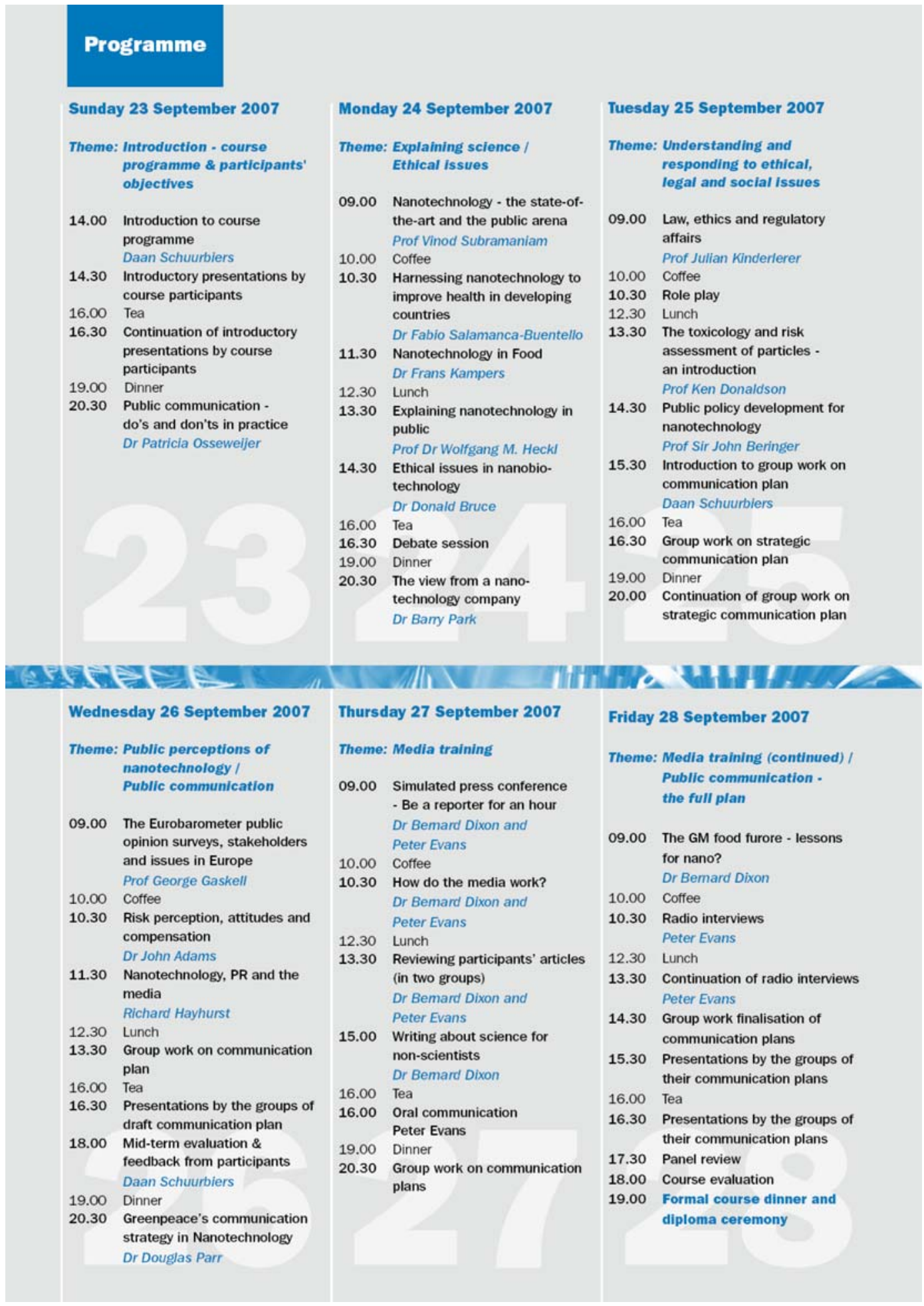

Fig. 3 Programme of the second course 'Public Communication and Applied Ethics of Nanotechnology' held in September 2007, showing the overall themes and the combination of lectures with practical work 


\section{References}

1. Allan R (2003) Nanotechnology: the next revolution to redefine electronics. Electron Des, May 26, 2003

2. Altmann J (2004) Military uses of nanotechnology: perspectives and concerns. Secur Dialog 35(1):61-79

3. Anton PS, Silberglitt RS, Schneider J (2001) The global technology revolution: bio/nano/materials trends and their synergies with information technology by 2015 . National Defense Research Institute (U.S.), Rand Corporation, Santa Monica

4. Beckwith J, Huang F (2005) Should we make a fuss? A case for social responsibility in science. Nat Biotechnol 23 (12):1479-1480

5. Bruce D (2007a) Human enhancement? Ethical reflections on emerging Nanobio-technologies. Available at: http:// files.nanobio-raise.org/Downloads/NBR-enhancement $\%$ 20final.pdf. Accessed 16 June 2009

6. Bruce D (2007b) Engaging citizens on nanobiotechnology using the democs game. Available at: http://files.nanobioraise.org/Downloads/NBR-democs.pdf. Accessed 16 June 2009

7. Cerutti H (2006) Know your nano! Information brochure of the publifocus "Nanotechnology, health and the environment". TA-SWISS, Bern

8. Cientifica (2007) Nanotech: cleantech quantifying. The effect of nanotechnologies on $\mathrm{CO} 2$ emissions. Available at: http:// cientifica.eu/attachments/054_052_CO2QuantificationWhite Paper.pdf. Accessed 16 June 2009

9. Collins HM, Evans R (2002) The third wave of science studies - studies of expertise and experience. Soc Stud Sci 32(2):235-296

10. Consoli L (2008) The intertwining of ethics and methodology in science and engineering: a virtue-ethicalapproach. Interdisc Sci Rev 33(3):233-242

11. Dunford R, Salinaro A, Caib L, Serpone N, Horikoshi S, Hidaka H, Knowland J (1997) Chemical oxidation and DNA damage catalysed by inorganic sunscreen ingredients. FEBS Lett 418:87-90

12. European Communities (2002) Science and society-action plan, 2002. Office for Official Publications of the European Communities, Brussels, p 30

13. European Communities (2004) Towards a European strategy for nanotechnology, May 2004. Office for Official Publications of the European Communities, Brussels, p 3

14. European Group on Ethics in Science and New Technologies to the European Commission (2007) Opinion on the ethical aspects of nanomedicine. Available at: http://ec.europa.eu/ european_group_ethics/activities/docs/opinion_21_nano_en. pdf. Accessed $1 \overline{7}$ July 2009

15. Federici G, Shaw BJ, Handy RD (2007) Toxicity of titanium dioxide nanoparticles to rainbow trout (Oncorhynchus mykiss): Gill injury, oxidative stress, and other physiological effects. Aquat Toxicol 84:415-430

16. Fisher E (2007) Ethnographic invention: probing the capacity of laboratory decisions. Nanoethics 1(2):155-165

17. Godman M, Hansson SO (2009) European public advice on nanobiotechnology-four convergence seminars. NanoEthics 3(1):43-59
18. Gorman ME, Groves JF, Shrager J (2004) Societal dimensions of nanotechnology as a trading zone: results from a pilot project. In: Baird D, Nordmann A, Schummer $\mathrm{J}$ (eds) Discovering at the nanoscale. IOS, Amsterdam

19. Guston DH, Sarewitz D (2002) Real-time technology assessment. Technol Soc 24(1-2):93-109

20. Hansson SO (2005) The right to be surveillance sensitive. J Inform Comm Ethics Soc 3:13-14

21. Joo SH, Cheng IF (2006) Nanotechnology for environmental remediation. Springer, London

22. Khushf G (2006) An ethic for enhancing human performance through integrative technologies. In: Bainbridge WS, Roco MC (eds) Managing nano-bio-info-cogno innovations: converging technologies in society. Springer, Dordrecht, pp 255-278

23. Lux Research (2008) Nanomaterials state of the market Q3 2008: stealth success, broad impact, Lux Research, New York, July 2008

24. Lux Research (2009) Nanomaterials state of the market Q1 2009: cleantech's dollar investments, Lux Research, New York, January 2009

25. Maynard AD, Aitken RJ, Butz T, Colvin V, Donaldson K, Oberdörster G, Philbert MA, Ryan J, Seaton A, Stone V, Tinkle SS, Tran L, Walker NJ, Warheit DB (2006) Safe handling of nanotechnology. Nature 444:267-269

26. McGregor J, Wetmore JM (2009) Researching and teaching the ethics and social implications of emerging technologies in the laboratory. Nanoethics 3(1):17-30

27. McGinn R (2008) Ethics and nanotechnology: views of nanotechnology researchers. Nanoethics 2(2):101-131

28. Mitcham C (2003) Co-responsibility for research integrity. Sci Eng Ethics 9:273-290

29. Mnyusiwalla A, Daar A, Singer P (2003) Mind the gap. Nanotechnology 14:9-13

30. Moor JH (2005) Why we need better ethics for emerging technologies. Ethics Inf Technol 7:111-119

31. Nanoforum (2009) Nanotechnology for healthcare. Available at: http://www.nanoforum.org/educationtree/healthcare/ healthcare.htm. Accessed 16 June 2009

32. Nordmann A (2007) If and then: a critique of speculative nanoEthics. Nanoethics 1(1):31-46

33. Nordmann A, Rip A (2009) Mind the gap revisited. Nature Nanotechnology 4:273-274

34. Osseweijer P, Spier R, de Cock Buning T (2009) Bioethics, public perceptions and communication courses for biotechnologists: lessons from practice for design and implementation. Sci Eng Ethics (submitted, currently under review)

35. Peterson C (2000) Taking technology to the molecular level. Computer 33(1):46-53

36. Poland CA, Duffin R, Kinloch I, Maynard A, Wallace WAH, Seaton A, Stone V, Brown S, MacNee W, Donaldson K (2008) Carbon nanotubes introduced into the abdominal cavity of mice show asbestos-like pathogenicity in a pilot study. Nature Nanotechnology 3:423-428

37. Rip A (2003) Constructing expertise: in a third wave of science studies? Soc Stud Sci 33:419-434

38. Robinson DKR (2009) Co-evolutionary scenarios: an application to prospecting futures of the responsible development of nanotechnology. Technol Forecast Soc Change. doi:10.1016/j.techfore.2009.07.015 
39. Roco MC, Bainbridge WS (2003) Converging technologies for improving human performance. Kluwer, Dordrecht

40. Roco MC, Bainbridge WS (eds) (2005) Nanotechnology: societal implications - maximizing benefit for humanity. Nanoscale Science, Engineering and Technology Subcommittee, Arlington

41. The Royal Society \& the Royal Academy of Engineering (2004) Nanoscience and nanotechnologies: opportunities and uncertainties. The Royal Society and The Royal Academy of Engineering, London

42. Sandler R, Kay WD (2006) The GMO-Nanotech (Dis) analogy? Bulletin of science. Tech Soc 26(1):57-62

43. Schuurbiers D, Fisher E (2009) Lab-scale intervention. EMBO Rep 10(5):424-427

44. Schuurbiers D, Sleenhoff S, Bennett DJ (2007) Issues to be RAISED: ethical and social considerations in nanotechnology research. Abstracts of the Workshop Philosophy and Engineering 2007, Delft University of Technology, October 29-31, 2007, p 72

45. Schuurbiers D, Osseweijer P, Kinderlerer J (2009) Implementing the Netherlands code of conduct for scientific practice - a case study. Sci Eng Ethics 15(2):213-231

46. Shrader-Frechette K (1997) Technology and ethical issues. In: Shrader-Frechette KS, Westra L (eds) Tech- nology and values. Rowman and Littlefield, Lanham, pp 25-30

47. Singer PA, Salamanca-Buentello F, Daar AS (2005) Harnessing nanotechnology to improve global equity. Issues Sci Technol 21(4):57-64

48. Snow CP (1959) The two cultures and the scientific revolution. Cambridge, UK: Cambridge University Press

49. The Nanotechnology Consumer Products Inventory (Woodrow Wilson International Center for Scholars, Washington DC (2006) Available at: http://www.nanotechproject.org/ consumerproducts. Accessed 16 June 2009

50. Van de Poel I (2008) How should we do nanoethics? A network approach for discerning ethical issues in nanotechnology. Nanoethics 2(1):25-38

51. Van der Burg S (2009) Imagining the future of photoacoustic mammography. Sci Eng Ethics 15(1):97-110

52. Weckert J (2007) Editorial. Nanoethics 1(1):1-2

53. Wennersten R, Fidler J, Spitsyna A (2008) Nanotechnology: a new technological revolution in the 21 st Century. In: Misra KB (ed) Handbook of performability engineering. Springer, London

54. Zwart SD, Van de Poel IR, Van Mil H, Brumsen M (2006) A network approach for distinguishing ethical issues in research and development. Sci Eng Ethics 12(4):663-684 